\title{
Study of the transport properties of composite solid electrolytes $\mathrm{LiClO}_{4}-\mathrm{MgAl}_{2} \mathrm{O}_{4}$
}

\author{
Dmitriy Alekseev ${ }^{1,2^{*}}$, Vyacheslav Khusnutdinov $^{1}$ and Yulia Mateyshina ${ }^{1,2,3}$ \\ ${ }^{1}$ Institute of Solid State Chemistry and Mechanochemistry SB RAS, Kutateladze 18, Novosibirsk, \\ 630090, Russia \\ ${ }^{2}$ Novosibirsk State University, Pirogova, 2, Novosibirsk, 630090, Russia \\ ${ }^{3}$ Novosibirsk State Technical University, Prospect Karla Marksa 20, Novosibirsk, 630073, Russia
}

\begin{abstract}
Magnesium-aluminum spinel $\mathrm{MgAl}_{2} \mathrm{O}_{4}$ was synthesized by mechanical treatment of a mixture of hydroxides followed by treatment of the solution at $80^{\circ} \mathrm{C}$ and sintering at $850^{\circ} \mathrm{C}$.. The obtained nanocrystalline sample with a specific surface area of $100 \mathrm{~m}^{2} / \mathrm{g}$ were used for the preparation of composite solid electrolytes (1-x) $\mathrm{LiClO}_{4}-\mathrm{xMgAl}_{2} \mathrm{O}_{4}$. It was shown that conductivity increases with the spinel concentration and goes through a maximum of $1.35 \cdot 10^{-2} \mathrm{~S} / \mathrm{cm}$ at $150{ }^{\circ} \mathrm{C}$ for composite $0.3 \mathrm{LiClO}_{4}-0.7 \mathrm{MgAl}_{2} \mathrm{O}_{4}$.
\end{abstract}

\section{Introduction}

At present, the search for new solid electrolytes is an urgent problem in solid state chemistry. These compounds are required to create solid state electrochemical devices such as supercapacitors, batteries, etc. The main task in the creation of solid electrolytes is to obtain a substance with high ionic conductivity. It is known that composite solid electrolytes obtained by heterogeneous doping are characterized by high ionic conductivity, mechanical and thermal stability in a wide temperature range [1]. These electrolytes consist of two components: an ionic salt (MX) and an inert oxide additive (A). The criteria for choosing an inert additive are a high specific surface area and chemical inertness to salt. As component $\mathrm{A}$, various highly dispersed oxides $\left(\mathrm{Al}_{2} \mathrm{O}_{3}, \mathrm{SiO}_{2}, \mathrm{TiO}_{2}, \mathrm{ZrO}_{2}, \mathrm{MgO}, \mathrm{CeO}_{2}, \mathrm{SnO}_{2}\right.$, etc.) can be used [2]. On the other hand, the second component, the ionic salt, must be thermally and electrochemically stable and have a satisfactory conductivity value. The literature contains information on composite solid electrolytes with various salts: $\mathrm{AgI}, \mathrm{AgCl}$, $\mathrm{LiClO}_{4}, \mathrm{MNO}_{2}, \mathrm{MNO}_{3}$ (where $\mathrm{M}$ are alkali metals), etc. [3,4]. Of practical interest are electrolytes with lithium-ion conductivity that are electrochemically stable in a wide range of voltages. Lithium perchlorate is characterized by low conductivity $\left(1 \cdot 10^{-5} \mathrm{~S} / \mathrm{cm}\right.$ at $\mathrm{T}=$ $200{ }^{\circ} \mathrm{C}$ ), but relatively high thermal $\left(\mathrm{T}_{\mathrm{dec}}=350{ }^{\circ} \mathrm{C}\right.$ ) and electrochemical stability (up to 3.5 $\mathrm{V}$ ), and can be used as a basic component to create solid composite electrolytes [5]. Ionic conductivity in various composite electrolytes $(1-\mathrm{x}) \mathrm{LiClO}_{4}-\mathrm{xA}$ (where $\mathrm{A}=\gamma-\mathrm{Al}_{2} \mathrm{O}_{3}, \mathrm{MgO}$ with a specific surface area $\mathrm{S}_{\mathrm{s}}=200-220 \mathrm{~m}^{2} / \mathrm{g}$ ) increases after addition of the up to $\sigma=$ $8^{*} 10^{-3} \mathrm{~S} / \mathrm{cm}$ (for $\gamma-\mathrm{Al}_{2} \mathrm{O}_{3}, \mathrm{x}=0.4-0.5$ at $200^{\circ} \mathrm{C}[6]$ ) and $\sigma=10^{-2} \mathrm{~S} / \mathrm{cm}$ (for $\mathrm{MgO}, \mathrm{x}=0.8-0.9$ at $\left.200^{\circ} \mathrm{C}[7)\right]$ ), goes through a maximum and decreases at high $\mathrm{x}$ values. Similar conductivity 
behavior is typical for many composite solid electrolytes and is explained by the enhanced ionic transport via interface regions. Magnesium oxide is a Lewis base [8], and several types of Lewis acid sites are present on the surface of alumina [9]. According to Maier's model [10], the main reason for the increase in conductivity in solid composite electrolytes is the specific adsorption of lithium cations on the oxide surface. Such an interaction is possible between the species of the Lewis acidic centers of ionic salt (for example, lithium cations $\left.\mathrm{Li}^{+}\right)$and Lewis basic centers $\left(\mathrm{O}^{2-}\right.$ or $\mathrm{OH}^{-}$ions $)$located on the oxide surface. The increase in the Lewis basicity of the oxide surface results in the increase in the ionic conductivity of the composite, provided that the contact surface area is similar.

In the present work, transport properties of composite solid electrolytes $\mathrm{LiClO}_{4}-\mathrm{MgAl}_{2} \mathrm{O}_{4}$ (which can also be represented as a complex oxide $\mathrm{MgO} \cdot \mathrm{Al}_{2} \mathrm{O}_{3}$ ) were investigated and compared with the results obtained earlier for composites with individual oxides $\mathrm{MgO}$ and $\gamma-\mathrm{Al}_{2} \mathrm{O}_{3}$.

\section{Experimental}

Lithium perchlorate was synthesized by the ion exchange reaction between aqueous solutions of lithium carbonate salt and perchloric acid (50-52\%), taken in stoichiometric ratios, followed by evaporation and crystallization of crystalline $\mathrm{LiClO}_{4} \cdot 3 \mathrm{H}_{2} \mathrm{O}$ hydrate. Spinel $\mathrm{MgAl}_{2} \mathrm{O}_{4}$ was synthesized from powders $\mathrm{Mg}(\mathrm{OH})_{2}$ and $\mathrm{Al}(\mathrm{OH})_{3}$, mixed in a molar ratio of $1: 2$, by activation in an AGO-2 planetary ball mill (with a mixture mass of $10 \mathrm{~g}$, stainless steel balls weighing $200 \mathrm{~g}$ and diameters $6 \mathrm{~mm}$ with an acceleration of $40 \mathrm{~g}$ ) for 10 minutes. The resulting mixture was treated at $80{ }^{\circ} \mathrm{C}$ for 8 hours (the mass ratio of water to solid phase was 10 ) with vigorous stirring. Subsequently, the material was filtered and dried at $25^{\circ} \mathrm{C}$ for 12 hours in the air. Thermal decomposition was carried out at $\mathrm{T}=850{ }^{\circ} \mathrm{C}$ for 3 hours in the air. The specific surface area of spinel was determined by the BET method from the analysis of the nitrogen adsorption isotherm on a Termosorb TPD 1200 analyzer $\left(\mathrm{S}_{\mathrm{s}}=100 \pm 20 \mathrm{~m}^{2} / \mathrm{g}\right)$.

Composite solid electrolytes $(1-\mathrm{x}) \mathrm{LiClO}_{4}-\mathrm{xMgAl}_{2} \mathrm{O}_{4}$, where $\mathrm{x}$ is the molar fraction, were synthesized by the ceramic method. The pre-dehydrated reagents were mixed and repeatedly heated to $240{ }^{\circ} \mathrm{C}$ for better distribution of the components in the composite. The analysis of the phase composition of the obtained composites was studied by X-ray phase analysis on a D8 Advance X-ray diffractometer (Bruker) using $\mathrm{Cu}-\mathrm{K} \alpha$ radiation in the angle range $5^{\circ}<2 \theta<90^{\circ}$ with a step size $\Delta 2 \theta=0.0195^{\circ}$ and a counting time of 35.4 s per step. Differential thermal analysis (DTA) of samples was carried on a calorimeter DSC-200 F3 MAIA, Netzsch at the temperature scan rate of $10 \mathrm{~K} / \mathrm{min}$. The powders of composite were compacted at 300-400 MPa together with two silver electrodes into pellets $0.1-0.2 \mathrm{~cm}$ in thickness and $0.5-0.6 \mathrm{~cm}$ in diameter. Relative density of pellets was $95-97 \%$ of theoretical. The conductivity was measured in a two-electrode cell in vacuum at a temperature 25-200

- $\mathrm{C}$ range in step isotherm mode using Hewlett Packard HP 4284A precision LCR meter (Japan) in the frequency range $20 \mathrm{~Hz}-1 \mathrm{MHz}$ at alternating current at voltage $10 \mathrm{mV}$. The conductivity values were calculated from at each temperature by analysis of $Z^{\prime \prime}=\mathrm{f}\left(Z^{\prime}\right)$ impedance plots.

\section{Results and Discussion}

\subsection{Structure and thermal properties}

According to XRD data, the synthesized $\mathrm{MgAl}_{2} \mathrm{O}_{4}$ is characterized by a spinel structure (PDF-2 73-2210) without impurities of other phases [Fig. 1 a]. The size of the $\mathrm{MgAl}_{2} \mathrm{O}_{4}$ 
particles, estimated using the Debye-Scherrer equation from the broadening of X-ray peaks, is about $10 \mathrm{~nm}$. According to electron microscopy data, spinel is a large agglomerate, consisting of spherical particles of approximately the same size (Fig.1 b). These differences between XRD and SEM methods can be explained by the high aggregation of nanodiamond particles and the insufficient resolution of the electron microscope
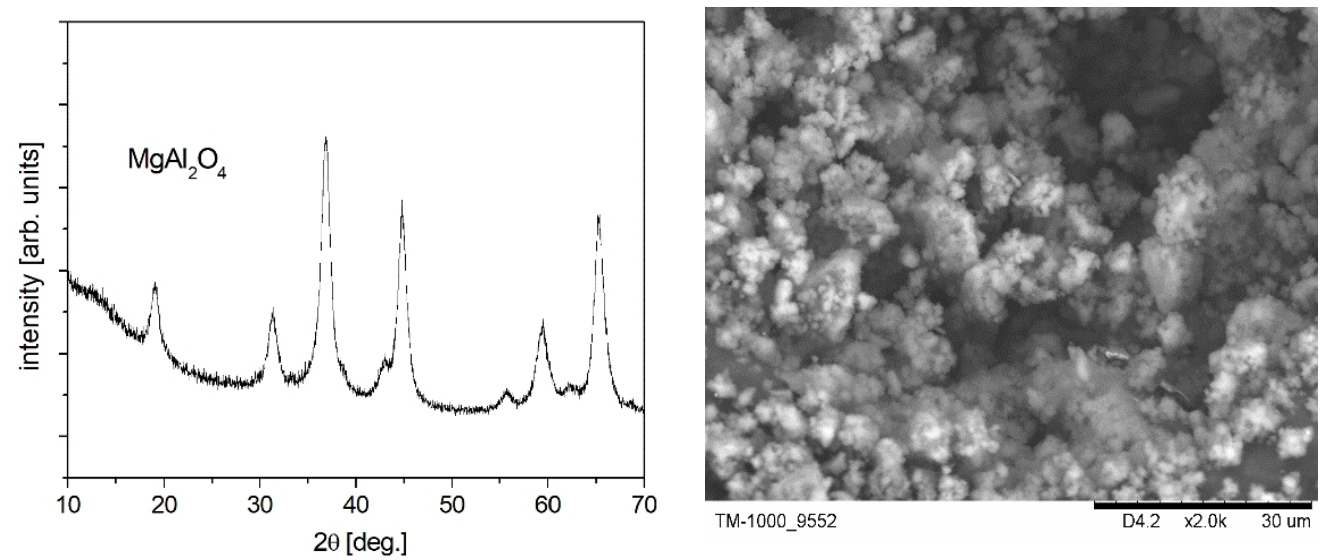

Fig. 1. X-ray diffraction patterns of $\mathrm{MgAl}_{2} \mathrm{O}_{4}$ (a); Electron microscopy image of $\mathrm{MgAl}_{2} \mathrm{O}_{4}$ (b).

The X-ray diffraction patterns of all studied composites $\mathrm{LiClO}_{4}-\mathrm{MgAl}_{2} \mathrm{O}_{4}$ show broadened reflections of nanocrystalline spinel (marked with *) and / or narrow peaks related to the phases of the trihydrate, monohydrate, or anhydrous phase of lithium perchlorate. With increasing salt concentration, the intensity of spinel phase reflections decreases. No peaks of other phases were observed, which indicates that there is no chemical interaction between the components during the synthesis of composites (fig. 2 a).
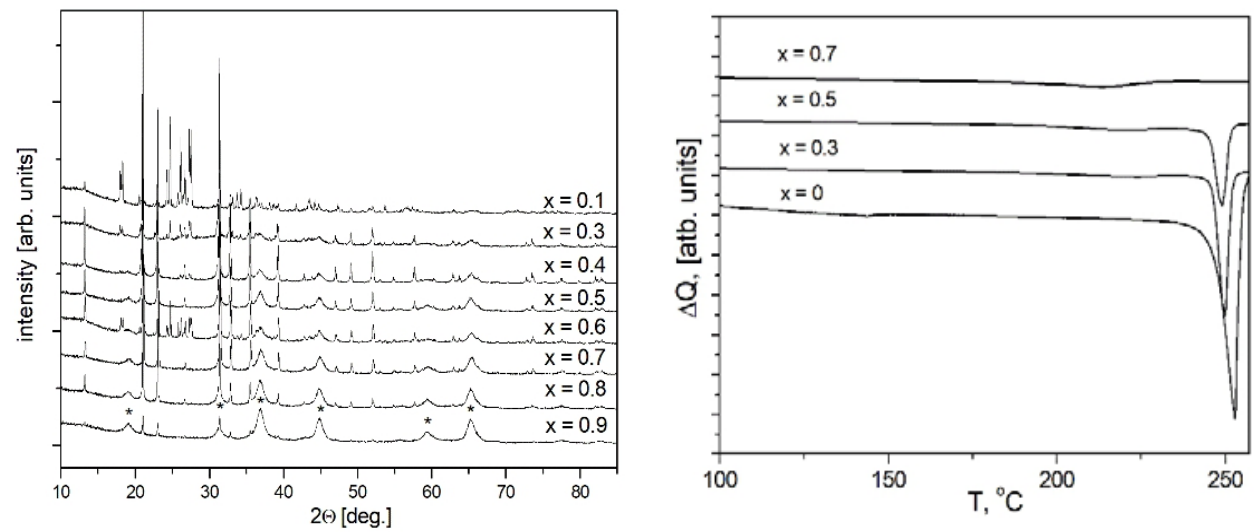

Fig. 2. X-ray diffraction patterns of $(1-\mathrm{x}) \mathrm{LiClO}_{4}-\mathrm{xMgAl}_{2} \mathrm{O}_{4}$ composites. Reflections of $\mathrm{MgAl}_{2} \mathrm{O}_{4}$ are marked by asterisks (a); DTA curves of the composites (1-x) $\mathrm{LiClO}_{4}-\mathrm{xMgAl}_{2} \mathrm{O}_{4}$, on the second heating run (b).

It is known that the process of thermal dehydration of $\mathrm{LiClO}_{4} \cdot 3 \mathrm{H}_{2} \mathrm{O}$ includes a stepwise removal of crystallization water, anhydrous lithium perchlorate appears at temperatures above $145{ }^{\circ} \mathrm{C}$ [11], these processes are observed on first heating of the mixture (1-x) $\mathrm{LiClO}_{4}-\mathrm{xMgAl}_{2} \mathrm{O}_{4}$ during the formation of composites. After cooling the 
samples in an argon atmosphere for the second heating, an endothermic effect is observed at the melting point of pure anhydrous $\mathrm{LiClO}_{4}$ (Fig. 2 b). As the content of the inert spinel additive increases, the melting peak of the composites shifts towards lower temperatures, which indicates a partial amorphization of the ionic salt. At $\mathrm{x}=0.7$, one can see a strong shift and a significant decrease in the intensity of the endothermic peak, which indicates a large degree of amorphization of lithium perchlorate in the composite material. A similar effect was observed previously in other systems of the «ionic salt-oxide» type [7, 12-15].

\subsection{Transport properties}

The study of the transport properties of composite materials was carried out by the method of impedance spectroscopy by analyzing the impedance hodogrophs at each temperature point. Typical Nyquist plots are shown in Fig. 3 a. Describing the plots obtained at different temperatures, we can say that they have a similar shape and consist of a slightly deformed semicircle located in the low-frequency region and describing the bulk component of the material conductivity, and a linear part characterizing the contribution of the electrodes. Impedance plots are typical for ionic conductors and can be satisfactorily described by a simplified equivalent circuit (Figure $3 \mathrm{~b}$ ) that includes the bulk impedance and impedance of the electrodes connected in series. The bulk impedance includes two elements: the bulk resistance $\mathrm{R}_{\mathrm{b}}$ and the constant phase element $C P E_{b}=\mathrm{Y}_{\mathrm{b}} \cdot \mathrm{W}^{\alpha 1}$; the electrode impedance comprises only the constant phase element $\mathrm{CPE}_{\mathrm{e}}=\mathrm{Y}_{\mathrm{e}} \cdot \mathrm{w}^{\alpha 2}$; where $\mathrm{Y}_{\mathrm{b}}$ and $\mathrm{Y}_{\mathrm{e}}$ are constants; $\alpha 1$ and $\alpha 2$ are the phase shift values.
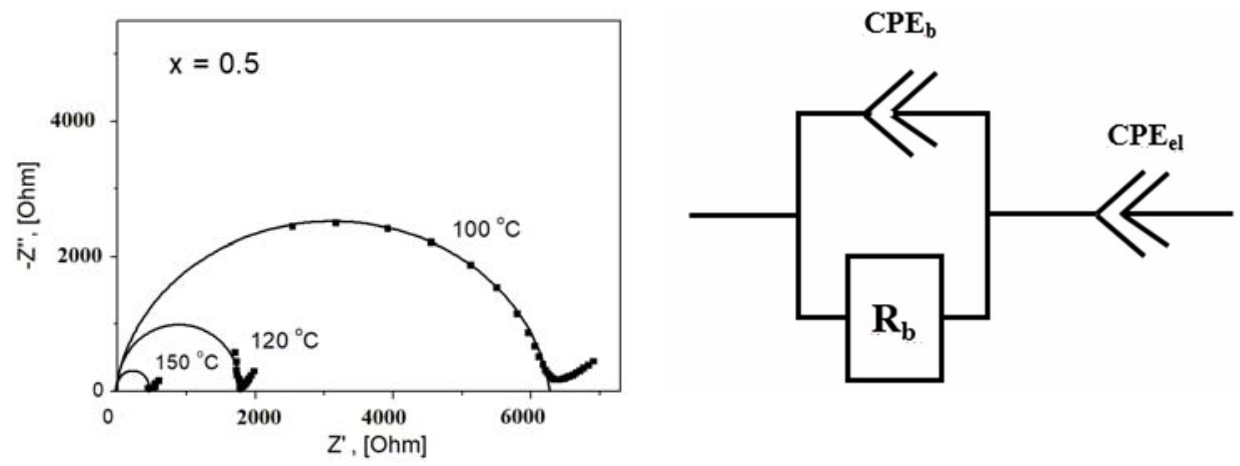

Fig. 3. Impedance plots for composite (1-x) $\mathrm{LiClO}_{4}-\mathrm{x} \mathrm{MgAl}_{2} \mathrm{O}_{4}$, obtained at 373, 393, $423 \mathrm{~K}$ (a); the equivalent circuit used for the data interpretation, where $\mathrm{R}_{b}$ is the bulk impedance; $\mathrm{CPE}_{\mathrm{b}}$ and $\mathrm{CPE}_{\mathrm{e}}$ are constant phase elements attributed to the bulk and electrode impedance, respectively (b).

The initial $\mathrm{LiClO}_{4}$ has conductivity $\sigma=3 \cdot 10^{-7} \mathrm{~S} / \mathrm{cm}$ at $\mathrm{T}=150{ }^{\circ} \mathrm{C}$ with activation energy of $1.05 \mathrm{eV}$ [6]. The addition of $\mathrm{MgAl}_{2} \mathrm{O}_{4}$ leads to an increase in the conductivity values depending on the composition (Fig. 4). The concentration dependence of conductivity passes through a maximum (Fig. $4 \mathrm{~b}$ ), composition $0.3 \mathrm{LiClO}_{4}-0.7 \mathrm{MgAl}_{2} \mathrm{O}_{4}$ is characterized by the maximum conductivity $\sigma=1.3 \cdot 10^{-2} \mathrm{~S} / \mathrm{cm}$ at $\mathrm{T}=150{ }^{\circ} \mathrm{C}$. The activation energy of the conductivity of composites decreases from $0.77 \mathrm{eV}$ for $\mathrm{x}=0.1$ to $0.44 \mathrm{eV}$ for $\mathrm{x}=0.7$, then increases to $0.55 \mathrm{eV}$ for $\mathrm{x}=0.9$. Similar conductance behavior typical of many composite solid electrolytes and is explained by the enhancement of ion transport across the interface regions [16-19]. 

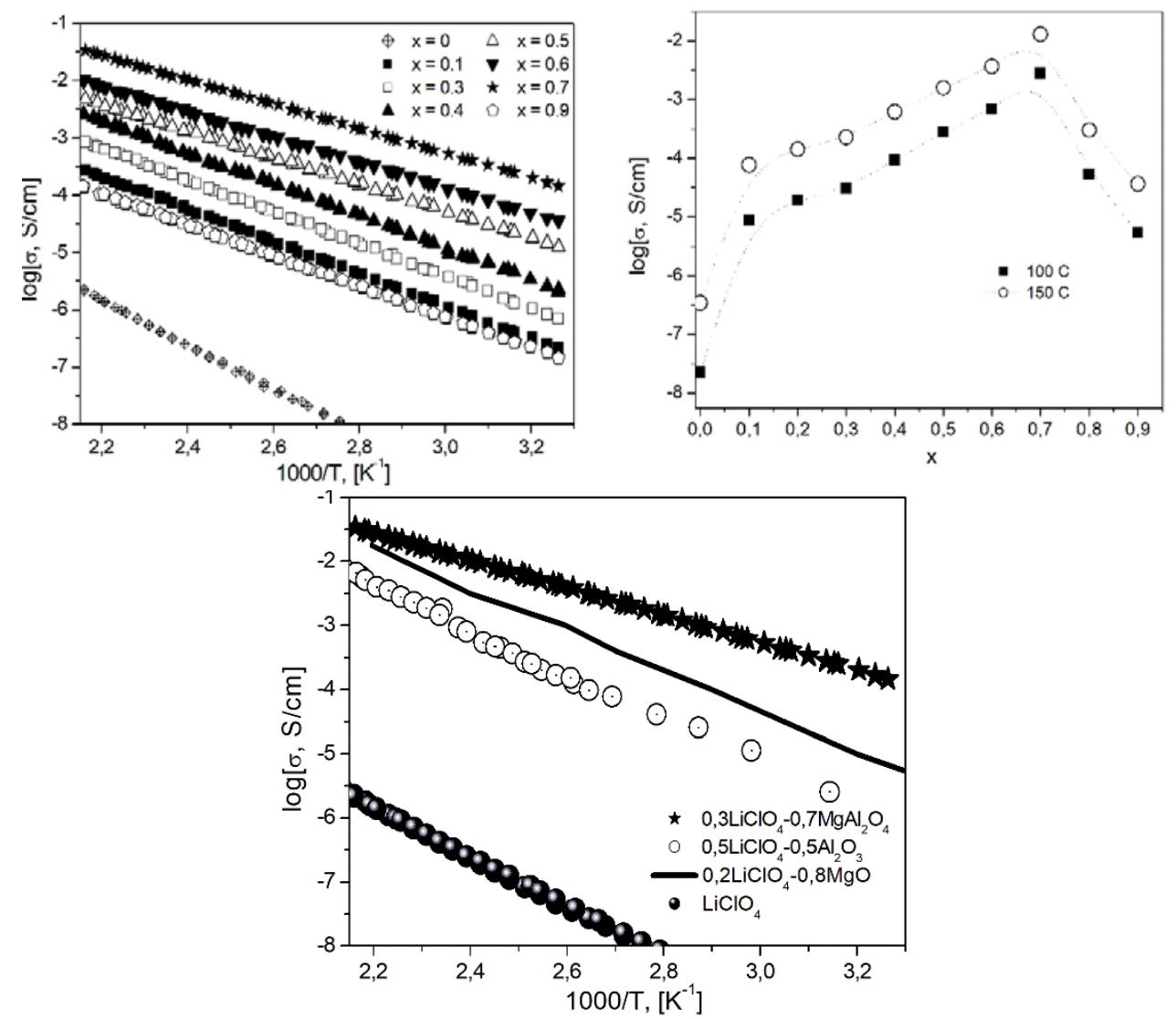

Fig. 4. Temperature (a) and concentration dependences of total conductivity for (1-x) $\mathrm{LiClO}_{4}-\mathrm{x}$ $\mathrm{MgAl}_{2} \mathrm{O}_{4}(0<\mathrm{x}<1)$ composites (b). Temperature dependences of composite electrolytes with the maximum conductivity of $0.5 \mathrm{LiClO}_{4}-0.5 \mathrm{Al}_{2} \mathrm{O}_{3}$ [6], $0.2 \mathrm{LiClO}_{4}-0.8 \mathrm{MgO}$ [7], $0.3 \mathrm{LiClO}_{4}-$ $0.7 \mathrm{MgAl}_{2} \mathrm{O}_{4}$ in comparison with the conductivity of pure $\mathrm{LiClO}_{4}(\mathrm{c})$. [7]

Figure 4 (c) shows a comparison of the transport properties of pure $\mathrm{LiClO}_{4}$ [7] and composite electrolytes with maximum conductivity with the addition of nanocrystalline aluminum oxide $0.5 \mathrm{LiClO}_{4}-0.5 \mathrm{Al}_{2} \mathrm{O}_{3}\left(\mathrm{~S}_{\mathrm{s}}{ }^{\mathrm{Al} 2 \mathrm{O} 3}=200 \mathrm{~m}^{2} / \mathrm{g}\right)$ [6], magnesium oxide $0.2 \mathrm{LiClO}_{4}-$ $0.8 \mathrm{MgO}\left(\mathrm{S}_{\mathrm{s}} \mathrm{MgO}=220 \mathrm{~m}^{2} / \mathrm{g}\right)$ and a composite with the addition of magnesium-aluminum spinel $0.3 \mathrm{LiClO}_{4}-0.7 \mathrm{MgAl}_{2} \mathrm{O}_{4}\left(\mathrm{~S}_{\mathrm{s}}=100 \mathrm{~m}^{2} / \mathrm{g}\right)$. The comparison shows that the conductivity of the composite with a spinel additive is higher in the entire investigated temperature range, and at low temperatures, the difference in conductivity values reaches two orders of magnitude (Fig. $4 \mathrm{c}$ ). Comparison of the conductivity values at $150^{\circ} \mathrm{C}$ per unit surface area of the inert oxide additive showed that the conductivity in the composite with spinel is more than 6 times higher than with $\mathrm{MgO}$ and 25 times higher than with $\gamma-\mathrm{Al}_{2} \mathrm{O}_{3}$. It was expected that spinel, as an inert additive, would behave similarly to oxides, given the lower $\mathrm{S}_{\mathrm{s}}$. To explain the obtained higher values of conductivity in composites with spinel, additional studies of the properties of surface centers of spinel additive by IR spectroscopy are required. Varying the conditions for the synthesis of $\mathrm{MgAl}_{2} \mathrm{O}_{4}$ makes it possible to obtain highly dispersed spinel with different values of the specific surface area, which opens up new possibilities for varying the transport properties of composite solid electrolytes. 


\section{Conclusions}

Composite solid electrolytes with the composition (1-x) $\mathrm{LiClO}_{4}-\mathrm{xMgAl}_{2} \mathrm{O}_{4}$ were synthesized and their phase composition and thermal properties were investigated by XRD and DSC methods, respectively. It was shown that by heterogeneous doping of lithium perchlorate with magnesium-aluminum spinel, it was possible to increase the conductivity of the ionic salt by more than 4 orders of magnitude. The composition $0.3 \mathrm{LiClO}_{4}-0.7$ $\mathrm{MgAl}_{2} \mathrm{O}_{4}$ has the highest conductivity value of $4.37 \cdot 10^{-2}$ at $200^{\circ} \mathrm{C}$. It was shown that the conductivity of the composite with a spinel additive is higher than conductivity of the composites with $\gamma-\mathrm{Al}_{2} \mathrm{O}_{3}$ and $\mathrm{MgO}$ additives in the entire investigated temperature range, and at low temperatures, the difference in conductivity values reaches two orders of magnitude.

The work was carried out with the support of the state assignment of the Institute of Solid State Chemistry and Mechanochemistry Siberian Branch of the Russian Academy of Sciences, project FWUS 0237-2021-0007.

\section{References}

1. J. Maier, J. Psys. Chem. Solids, 46 (1987)

2. N.F. Uvarov, Composite solid electrolytes, Russian ed. Nauka Pbls, Novosibirsk (2008)

3. P. Chowdary, V. B. Tare, J. B. Wagner, J. Electrochem. Soc., 132 (1985)

4. N.F. Uvarov, E. F. Hairetdinov, I. V. Scobelev, Solid State Ionics, 86 (1996)

5. D.V. Alekseev, Yu. G. Mateyshina, V.Yu. Komarov, E.V.Sevast'yanova, N. F. Uvarov, Materials Today: Proceedings, 31 (2020)

6. A.S. Ulihin, N.F. Uvarov, Yu. G. Mateyshina, L.I. Brezhneva, A.A. Matvienko, Solid State Ionics, 177 (2006)

7. A.S. Ulihin, N.F. Uvarov, ECS Transactions, 51 (2009)

8. I. A. Ekimova and T. S. Minakova, Protection of Metals, 44 (2008)

9. G. D. Chukin, The structure of aluminum oxide and catalysts hydrodesulfurization. Reaction mechanisms, Moscow: Paladin Printing House, Printa LLC (2010)

10. J. Maier, Solid State Ionics, 139 (1995)

11. S.I. Ivlev, D.V. Akimov, N.B. Egorov, F. Kraus, Monatshefte fur Chem., 147 (2015)

12. N.F. Uvarov, P. Vanek, M. Savinov, V. Zelezny, J. Studnicka, J. Petzelt, Solid State Ion., 127 (2000)

13. K. Tadanaga, K. Imai, M. Tatsumisago, T. Minami, J. Electrochem. Soc., 147 (2000)

14. K. Tadanaga, K. Imai, M. Tatsumisago, T. Minami, J. Electrochem. Soc., 149 (2000)

15. Mateyshina Yu., Slobodyuk A., Kavun V., Uvarov N., Solid State Ionics., 324 (2018)

16. J. Maier, Prog. Solid State Chem., 23 (1995)

17. S. Jiang, J.B. Wagner Jr., J. Phys. Chem. Solids, 56 (1995)

18. H.E. Roman, A. Bunde, W. Dietrich, Phys. Rev., 34 (1986)

19. N.F. Uvarov, Solid State Ion., 136 (2000) 